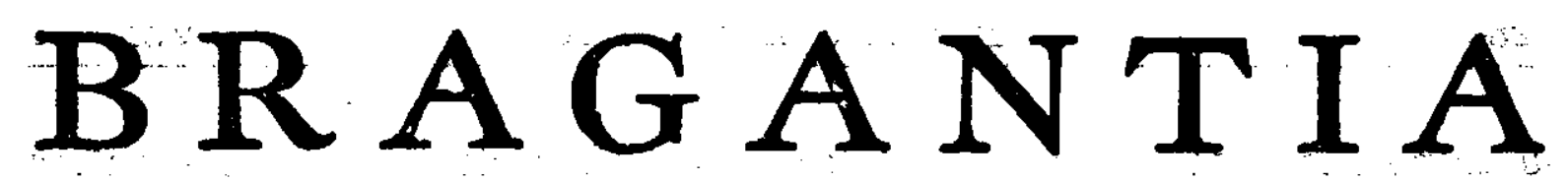

Boletim Técnico da Divisão de Experimentaşão e Pesquisas IN STITUTO A GRONÔMICO

Vol: 6

Campinas, Julho de 1946

N. 7

\title{
ESTUDO CARIOMÉTRICO DOS POLIPLÓIDES DE COFFEA
}

(Discussão do problema e primeiros resultados)

Caryometric researches on Coffea polyploids

(Discussion of the problem and preliminary results)

Giórgio Schreiber $\left(^{*}\right)$

I - Introdução

II - Técnica

a) esclarecimentos teóricos

b) escolha do material

c) técnica cariométrica

d) elaboração estatística

III - Consideraçôes sôbre o mạterial estudado e observacôes sôbre os resultados

IV - Conclusỡes gerais e discussão

$\mathrm{V}$ - Resumo

- Summary

- Literatura citada

- Explicação das figuras

\section{$1-$ I N T R O D U Ç Ã O}

Num trabalho precedente (Schreiber 34), foi examinado teòricamente o problema do crescimento do núcleo durante a interfase e as suas variaçzes em tamänho, para maior ou para menor, durante o desenvolvimento embrionário e postembrionário.

Tal estudo, executado por método cariométrico-estatístico, constitui uma tentativa de análise do processo de duplicação do genoma e suas variaçōes quantitativas. Entretanto, ainda não está perfeitamente esclar recido se o volume nuclear exprime fielmente o que se passa no genoma nas diferentes condições examinadas. De fato, na literatura existente sôbre o assunto acha-se ainda aberta à discussão se o número de cromossômios

(*) Do laboratório de citogenética do Instituto Butantã (São Paulo, Brasil) e da Escola Livre de Sociologia e Política de São Paulo. 
é proporcional ao volume do núcleo, à superfície do mesmo ou a outros valores quantitativos celulares (superficie celular por exemplo). $O$ assunto foi detalhadamente discutido por Geitler (20); limitámo-nos, no presente trabalho, a abordar o assunto em seus têrmos mais simples, isto é, se o volume nuclear é realmente proporcional ao número de cromossômios, ou, mais exatamente, a valores múltiplos do genoma haplóide ; ou, pelo menos, em qual fase do ciclo nuclear esta proporção é válida.

Achamos especialmente indicados para esclarecer êste problema os seguintes campos de pesquisas:

1) - 0 estudo do volume nuclear durante o ciclo interfásico, no qual o genoma multiplica-se duas ou mais vêzes, como no caso da endomitose. Vários autores empreenderam êste estudo há anos, mas não sempre sôbre material que pudesse ser confrontado e generalizado (Infusórios). Mais recentemente, Wermel e colaboradores (39), através de observações diretas e cinematografia das culturas em vitro, confirmaram os resultados de pesquisas cariométricas. Este problema é, a nosso ver, de natureza básica.

2) - O confronto entre núcleos de organismos da mesma espécie, mas com números total ou parcial de cromossômios diferentes (poliplóides ou polissômicos). Nesta categoria agrupa-se a quase totalidade de pesquisas feitas sôbre o problema desde as primeiras de Boveri e de Herbst sôbre material embrionário experimental, até as clássicas de Gerassimoff, Marshal, Wettstein, Gates, Lindstrom, Winkles, etc. (cit. Wilson (41), Bhaduri, (11) etc., sôbre os vegetais, e de Dobzhansky, (15) Fankhauser, (17) Artom (1) Barigozzi (2) e outros, sôbre material animal. Muitas destas pesquisas, porém, nem sempre se referem ao núcleo, mas sim à célula ; muitos fatôres diferentes podem modificar o resultado em tal caso.

3) - O estudo dos fenômenos de redução meiótica ou de diminuição durante o desenvolvimento embrionário. Os primeiros, especialmente, são particularmente apropriados para revelar as relações entre volume nuclear e cromossômios, pois as variaçóes dêstes estão perfeitamente esclarecidas em tôdas as fases do processo [Jacobi $(\mathbf{2 6}, \mathbf{2 7}, \mathbf{2 8})$, Sauser (32), Freerksen (19), G. Hertwig (23), Wermel (38), B. Schreiber (33)]. Num trabalho recente, G. Schreiber (35) estudou, sob êste ponto de vista, a espermatogênese dos Ofídeos, esclarecendo : 1) a absoluta correlação positiva entre volume nuclear e valor múltiplo do genoma entre os elementos da série meiótica (meiocitos de $1 .^{\mathrm{a}}$ e $2 .^{\mathrm{a}}$ ordem e espermatides) ; e 2) a existência no ciclo interfásico das espermatogonias de um estádio ao valor $3 n$ que confirma uma série de indicações existentes na literatura cariométrica e cuja interpretação é ainda muito discutida. Nestas mesmas pesquisas foi tamběm confirmada a variação de volume correspondente a um intervalo de duplicação durante o ciclo interfásico (2:4).

No presente trabalho queremos examinar, sob o ponto de vista acima discutido, uma série de poliplóides de café (Coffea), cujo estudo botânico e genético está sendo desenvolvido há alguns anos nas Secções de Genética e de Citologia do Instituto Agronômico de Campinas. Aos Chefes dessas 
Secções, Drs. C. A. Krug e A. J. T. Mendes, desejamos exprimir publicamente a nossa profunda gratidão por nos terem proporcionado a oportuni- dade de levar a efeito estas pesquisas com o material tão precioso e tão generosamente pôsto à nossa disposição.

Achamos necessário focalizar detalbadamente os fundamentos teóricos do método empregado e tôdas as possíveis causas de êrro ainda que consideremos os resultados obtidos como preliminares, devido ao pequeno número de casos estudados e aos fatos inesperados que as próprias pesquisas revelaram, como no caso de Coffea congensis, os quais aguardam ulteriores e mais profundas pesquisas.

\section{I T C N I C A}

\section{a) Esclarecimentos teóricos}

O método usado consiste essencialmente na medida do volume nuclear num complexo de núcleos suficientemente grande para se poder depois analisar estatìsticamente a sua variabilidade.

Foram desenhados, de cada exemplar, no mínimo, 100 núcleos ; sôbre êstes desenhos foram medidos os diêmetros maior e menor; o volume dos núcleos era calculado como se fôsse uma esfera de diâmetro igual à média dessas medidas. Os volumes ou os diâmetros correspondentes foram grupados em classes de frequência, desenhados os polígonos ou os histogramas, e calculados os parâmetros estatísticos.

Devemos aqui frisar que, na realidade, as variações observadas numa população de núcleos, não são devidas sòmente à variabilidade flutuante casual, mas, essencialmente, ao crescimento próprio dos núcleos na interfase. As curvas e os histogramas, construídos com os diâmetros, e com os volumes, não são, portanto, "normais". Apesar disso, para ter elementos de confronto entre as diversas curvas, foram calculados os parâmetros (média, desvio padrão, coeficiente de variação, valor modal); sòmente o valor modal, porim, por motivos que serão esclarecidos adiante, foi considerado o parâmetro de maior valor nestes estudos.

Como já foi pôsto em evidência por vários autores (I. Fischer, (18) Thomı son D'Arcy (๕7) Wermel (๕9) etc.), êste método de estudo estatístico permite analisar o processo de crescimento dos núcleos, obtendo conclusões de ordem dinâmica do estudo de um material estático como é uma massa de núcleos fixados em preparações histológicas. De fato, se a variabilidade do tamanho é determinada pelo erescimento, as frequências dos volumes observados são inversamente proporcionais às velocidades de crescimento ; encontraremos, portanto, num determinado momento, núcleos de tamanho diferente : as frequências máximas corresponderão. a etapas do crescimento. Este fato foi confirmado experimentalmente por Wermel e Portugalow (9) com o confronto das curvas de frequências cariométricas as curvas volumétricas reveladas cinematogràficemente nas culturas in vitro.

Assim, pode-se confrontar etapas de crescimento de núcleos de uma mesma populagãa nuclear, e, portanto, estudar o ritmo de crescimento 
dêstes núcleos ; pode-se também confrontar populações diferentes de núcleos, porém, em etapas correspondentes, isto é, fases homólogas das variaçóes quantitativas do genoma.

Foram levantadas várias críticas a êste gênero de estudos, especialmente por ser o aumento volumétrico do núcleo devido não sòmente ao real aumento do genoma, mas também a variações de ordem físico-química, como as embebições de água, variações de estado coloidal, etc. Devemos, todavia, frisar que qualquer que seja a natureza destas variações mesmo que se conheçam os mecanismos físicos ou químicos que a determinam, quando os resultados finais do aumento se dão em relações simples e constantes e perfeitamente paralelas às variaçóes simples e constantes do genoma, é evidente que elas são quantitativamente controladas pelas variações dêsse genoma. Com isto não queremos absolutamente esquecer que existem. variações controladas por determinados gens (Dobzhansky (15); porém. o caso mais geral da variação de tamanho durante a interfase nos mostra geralmente uma simples relação quantitativa entre o genoma e o volume.

As recentes pesquisas sôbre o metabolismo dos ácidos nucléicos e as: relações entre núcleo e citoplasma durante êste metabolismo poderiam sugerir algo sôbre a natureza das relaçós entre o genoma e o ambienteinterno nuclear que determina o seu volume. Especialmente interessantes: se nos deparam tais relaçóes durante a segmentação embrionária, onde há, às vêzes, passagem de material citoplásmico para o núcleo progressivamente durante as sucessivas gerações de blastomeros (Godlewsky). (22)

Em tudo isto, portanto, não devemos confundir os fenômenos com: os seus mecanismos; os resultados finais destas pesquisas nos autorizom. a utilizar as medidas cariométricas como meio de análise quantitativa do. genoma em falta de outros métodos mais específicos e sutis.

Em um trabalho de Painter e colaboradores (12) o mesmo conceito: foi discutido como resultado das pesquisas estatístico-cariométricas dos tecidos neoplásticos; as diferentes classes de volume correspondem aos: diferentes graus de poliploidismo ou de politenia, verificadas pelo examecitológico do número de cromossômios e do seu tamanho (número de cromonemas). Conclusões análogas foram alcançadas recentemente por D'Ancona, (13,14) Beams e King (4) e Sulkin. (35).

\section{b) Escolha e preparo do material}

Para o estudo cariométrico, o material ideal seria um tecido de núcleos: perfeitamente csféricos como o do fígado dos mamíferos e os elementos: da série espermatogenética ; além disso, o figado, pelos conhecidos fenômenos de endomitose ou endosquise foi um dos objetos mais estudados. pelos primeiros autores que se ocúparam de eitologia quantitativa. $O$ material vegetal e em particular as pontas vegetativas das raízes representam, por outro lado, um b́timo material para o estudo de núcleos não. esféricos, tendo em geral núcleos elipsoides a dois eixos (elipsóides de rotação) orientados com o eixo maior no sentido do eixo radieal. $O$ fato de serem cstes elipsbides rigorosamente orientados nos oferece a possibilidade de eliminar as objeçoes feitas por Meyer (34) aos estudos cariométricos nos: 
tecidos com núcleos nạo esféricos, e não orientados. Tivemos ocasião de verificar em pesquisas ainda não divulgadas que, nas pontas vegetativas das rázes, a variação do volume nuclear durante o crescimento interfásico se dá principalmente pelo aumento do eixo longitudinal. Os núcleos discoidais originados depois de telófase se tornam primeiramente esféricos pelo aumento do eixo longitudinal e depois elipsoidais em virtude da constância do mesmo fator ; o eixo maior dêsse elipsóide atinge um máximo na prófase. A análise estatística dêste fenômeno mostra com boa evidência as etapas do crescimento interfásico.

O material de que nos utilizamos já se encontrava na maior parte preparado em cortes transversais, sendo menos evidentes aí as variações acima mencionadas ; tivemos, pois, de considerar os núcleos como esféricos e as variações devidas ao acaso. $O$ estudo futuro de cortes longitudinais poderá esclarecer a variação devida ao crescimento interfásico; porém, o exame realizado serviu perfeitamente para se estabelecer um confronto entre plantas pertencentes a uma série poliploide : as variaçóes do crescimento interfásico em cortes transversais não influem sensivelmente de modo a impedir um tal confronto; além disso, é de se supor que essas variações sejam paralelas em tôdas as plantas estudadas.

As raízes colhidas no Instituto Agronômico de Campinas, sendo fixadas em "Craf" e incluídas em parafina pelo método do álcool butílico. Seccionadas transversalmente a $8 \mu$ de espessura e coloridas pela hematoxilina férrica de Heidenhain, destinavam-se à contagem de cromossômios; as lâminas foram em seguida cedidas para o nosso estudo pelo Dr. A. J. T. Mendes, da Secção de Citologia daquele Instituto. Uma parte do material foi por nós seccionado e colorido segundo a mesma técnica, tendo recebido as raízes incluídas em parafina daquela mesma procedência.

Foram duas as espécies estudadas : Coffea congensis Froehner, diploide $2 \mathrm{n}=22$, Krug, 24) e Coffea arabica L. com suas formas di-haploide ( $2 \mathrm{n}=22$, Mendes e Bacchi, 30), tetraplóide $(2 n=44, K r u g, 24)$, hexaplóide $(2 n=66$, Krug 25) e octoplóide ( $2 n=88$, Krug, 25).

\section{c) Técnica cariométrica}

Limitámo-nos na presente pesquisa a um pequeno número de pontas radicais, escolhendo sòmente aquelas nas quais as medidas pudessem ser executadas com suficiente segurança. Em cada indivíduo foram medidos sòmente os núcleos das células do periblema, entre os dois ou três primeiros extratos debaixo do dermatógeno até o início do pleroma. Limitámo-nos também à zona imediatamente superior 80 ponto vegetativo sem atingir a zona superior da raiz, onde se verifica geralmente o maior elongamento das células e onde se dão os fenômenos de poliploidismo interno ou "polisomaty", estudados por Berger (5-10) e outros autores [(Langlet (29), Erwin (16), Genseheff e Gustawson (21), Witkuss (42)] com consequente aumento do volume nuclear.

Tódas as medidas foram efetuadas em desenho à câmara clara dos núcleos, usando objetiva de imersão 1/12 ap. 1,30 e ocular acrom 4, e a fôlha do desenho à altura do pe do microsc6pio. Esta disposiçăo proporciona 
uma ampliação de 1440 diâmetros e, portanto, cada milímetro do desenho representa 0,7 micra.

Em cada raiz foram medidos, pelo menos, 100 núcleos (às vêzes 200) ; pelas razões de limites especiais acima mencionados, nas raízes de Coffea êste número não pode ser muito maior.

Sôbre os desenhos foram depois medidos, em cada núcleo, os dois diâmetros cruzados, maior e menor, e com a média aritmética entre êstes foi calculado o volume da esfera. Adotamos êste sistema, que, aliás, já foi usado por muitos autores (I. Fischer, Clara, Jacobi, Beans e King, etc., citados em Schreiber $(\mathbf{3 4 , 3 5 )}$ por ser infinitamente mais fácil e rápido do que outros usados por outros pesquisadores como, por exemplo, a determinação da área do desenho com o planímetro. Nos núcleos pequenos, a diferença entre os dois diâmetros é insignificante, ao passo que nos hexa-e octoplóides é mais evidente ; aliás, nestes núcleos, provàvelmente, o efeito do crescimento interfásico e também as contrações devidas às manipulações histológicas fazem-se sentir mais.

Nas pesquisas clássicas de Wettstein (40) que, porém, se referem especialmente ao volume celular, o efeito do alto grau de poliploidia se manifesta com uma menor regularidade e muito diferente nos híbridos, ao passo que nesta série estudada, a correlação parece ser bem clara em tôda a extensão da série. Devemos salientar, porém, que o volume celular é algo bem mais complexo do que o nuclear e as relaçóes entre volume e a superfície na célula estão sujeitas a maior número de fatôres do que no núcleo.

\section{d) - Elaboração estatística dos resultados.}

Relatamos aqui sòmente os resultados das medidas sôbre 11 raízes, escolhendo entre as muitas estudadas apenas aquelas que deram curvas de frequência mais fàcilmente analizáveis e deixando de lado as que, por serem muito mais irregulares, mal se prestavam a uma estimação do modo e à consequente comparação com as demais. A variabilidade das outras séries (polimodais e irregulares) poderia ser interpretada de vários modos, porém não queremos entrar em discussões que poderiam nos desviar muito do assunto estritamente limitado desta pesquisa ; limitémo-nos à comparação das poucas curvas regulares e simples que provàvelmente mostram uma certa sincronia nos núcleos. De cada grau de poliploidia foram medidas, ao menos, duas raízes diferentes, da mesma planta ou não, e, como se pode constatar do exame simples dos gráficos, os resultados são geralmente bem concordantes. No caso de Coffea congensis (séries n. ${ }^{\circ} 3$ e 4) a diferença com as correspondentes séries de 22 cromossômios de Coffea arabica é, pelo contrário, bem significante e, como será discutido mais adiante, êste fato merece um estudo mais aprofundado em ulteriores pesquisas.

Os resultados das medidas nucleares foram agrupados pelos diâmetros em classes de frequência de $0,5 \mathrm{~mm}$ (no desenho) e calculados a média aritmética, desvio padrão e valor normal (modo); o mesmo foi feito para os valores volumétricos calculados para cada classe de diâmetros $\left({ }^{*}\right)$.

(*) Por todos éstes célculos estamos sumamente gratós ao Prof. Gírgio Mortara, Consultor Técnico da Comissão Nacional do Recenseamento do Rio do Janeiro. 
Como já foi salientado antes, a população de núcleos não tem uma variação "normal", e, portanto, qualquer cálculo baseado sôbre a normalidade seria mais ou menos aproximado, mas não real. Portanto, êste estudo foi limitado à comparação da variação do número de cromossômios com a variação do valor modal dos volumes nucleares. A escolha do valor modal, entre os parâmetros calculados foi já esclarecida pelos fundamentos teóricos do método cariométrico.

Para a série dos valores modais dos volumes e os números de cromossômios correspondentes, foi calculada a equação de regressão e assim traçada a reta interpolar; com relação a esta equação foi calculado o "êrro de estimação" (Sy). Êste é o único elemento que nos proporciona um critério de julgamento suficiente para os dados estatísticos sôbre êste matẹial. Qualquer outro critério geralmente usado seria afetado pelo fato de não serem as curvas normais. Um outro critério simples para julgar a relação entre volume e número de cromossômios por nós utilizado nesta pesquisa foi o de calcular a razão entre o volume nuclear (valor modal) e número de cromossômios. Estes valores, calculados para cada indivíduo, estão reunidos na Tab. IV e mostram uma notável homogeneidade.

Juntamente com a documentação estatística da variação do volume nuclear em relação ao valor poliplóide, achamos interessante dar a documentação fotográfica que nos proporciona um elemento de apreciação e de controle bastante significativo. As microfotografias (1-5) mostram os cortes das pontas radicais das plantas de diferente número de cromossômios da série $2 \mathrm{n}=22,44,66,88$.

Os dados calculados estão reunidos nas tabelas I-IV, sendo na tabela as indicaçôes da variabilidade dos diâmetros das 11 séries medidas ; a tabela II contém a média aritmética (M), o desvio padrão (o) e o coeficiente de variação (Vm) dos diâmetros e dos volumes; a tabela III contém a média, a mediana e o valor normal dos diâmetros e dos volumes ; o valor mediano foi determinado gràficamente sôbre a curva cumulativa das frequências ; o valor normal (modo) foi determinado numèricamente pela perequação da série das frequências do diâmetro $d$ verificada depois gràficamente; a tabela IV contém as razōes: volume nuclear $/ n .^{\circ}$ de cromossômios.

\section{III - CONSIDERACÕES SÔBRE O MATERIAL ESTUDADO E OBSERVAÇÕES SÔBRE OS RESULTADOS}

Damos aqui resumidos os dados de protocolo de todos os indivíduos estudados.

N. 1. e 2. Coffea arabica var. monosperma Ottoländer e Cramer.

Prot. (Campinas) F. 2220.

$2 n=22$.

Fixador : Craf.

Siāo dois pontos radieais da mesma planta em corte transversal.

Microfoto Fig. 1. 
N. 3 e 4. Coffea congensis Froehner

Prot. (Cumpinas) F. 2113.

$2 \mathrm{n}=22$.

Fixador : Craf.

Duas raízes da mesma planta em corte transversal.

Microfoto Fig. 2.

N." 5, 6 e 7. Coffea arabica.

$2 \mathrm{n}=44$.

Fixador : Craf.

Cortes transversais em três plantas diferentes.

Prot. (Campinas) : N. $5:$ F. 2241 C. arabica var. typica.

N.॰ 6: F. 981 C. arabica typica $44 \times$ bullata 66 .

N. 7 : F. 992 C. arabica typica $44 \times$ bullata 66.

Microfoto n.* 6 fig. 3 .

N. ${ }^{\circ} 8$ e 9. Coffea arabica var. bullata Cramer.

$2 \mathrm{n}=66$.

Cortes transversais. Duas plantas diferentes.

n. 8 Prot. (Campinas): F. 594 Fixador Craf.

Microfoto N.0 8 Fig. 4.

N. ${ }^{\circ} 10$ e 11. Coffea arabica var. bullata Cramer.

2n $=88$.

Fixador Craf. Cortes transversais

Duas raizes da mesma planta. Prot. (Campinas) F. 1005.

O gráfico I resume os polígonos de frequência dos 11 indivíduos estudados grupados de acôrdo com o número de cromossômios. As curvas estão bastante regulares e bem concordantes entre os grupos singulares de mesmo número de cromossômios. Faz exceção uma das duas curvas de 66 cromossômios ; porém foi considerada junta com as outras pelo fato de contarmos sòmente com êstes dois exemplares hexaplóides.

A variação progressiva do valor modal é apreciável, mesmo à primeirà vista, apesar de serem os polígonos de frequência notàvelmente interferentes entre si. Fste último fato deve, porém, ser encarado sob a luz das premissas do método usado, pois as populaçố de núcleos estão tôdas "em movimento cariocinético". Para cada indivíduo existe ao menos uma variabilidade fisiológica dos valores volumétricos nucleares no intervalo $2 n-4 n$ do erescimento interfásico. Para têrmos um elemento de confronto absolutamente certo dever-se-ia confrontar fases rigorosamente iguais da excursão interfásica, ou, por exemplo, sòmente as prófases. Neste caso, porém, provàvelmente intervirão outros fatôres de variabilidade volumétrica como as deformações que precedem a ruptura da membrana nuclear ou fatôres de imbebição que, por enquanto, não sabemos controlar.

Como já foi lembrado, no estudo do crescimento interfásico do núcleo das espermatogonias tivemos ocasião de demonstrar que nas variações volumétricas dêste período o núcleo apresenta uma excursão bem evidente de um intervalo de duplicação $(2 n-4 n)$. Além disso, existe um estádio 
muito bem evidente e muito constante em tôdas as espécies examinadas (ofídios) equivalente mais ou menos à metade do intervalo interfásico, isto é, com boa aproximação estatística ao volume correspondente a $3 \mathrm{n}$. Este estádio, que denominamos "sesquifase", foi verificado também por outros autores nos estudos cariométricos de inúmeros tecidos e organismos

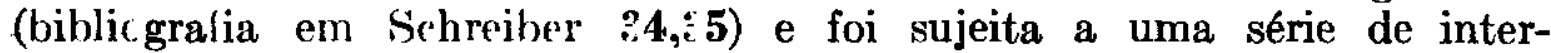
pretações diferentes e muito discutíveis. Baseados nesta difusão dêste estádio intermediário durante o intervalo de duplicação interfásica, temos elementos suficientes para supor que os núcleos dos tecidos somáticos em geral se encontrem na maior parte (isto é, com a frequência máxima e, portanto, por um período mais longo de tempo) nesta etapa intermediária; e não nos parece improvável que também no caso do Café, os núcleos, por terem na sua maioria um valor modal único e bem evidente, e êstes valores modais seren bem estritamente correlatos aos correspondentes valores múltiplos dos genomas, estejam provàvelmente na mesma "fase" do ciclo interfásico. Fm resumo, os valores modais das diferentes raízes são formados por núcleos que se encontram em fases homólogas de crescimento e, portanto, perfeitamente confrontáveis.

O gráfico II mostra com boa evidência a correlação positiva entre n. ${ }^{\circ}$ de cromossômios e volume nuclear. $O$ cálculo do "êrro de estimação" indica que todos os pontos estão entre os limites fiduciais da variabilidade casual ( $\pm 3 \mathrm{Sy}$ ). Calculamos também, pela fórmula

$$
r=\sqrt{1-\frac{S^{2}}{\sigma y^{2}}}
$$

o coeficiente de correlação, que resulta ser de 0.99 .

Devemos agora esclarecer o caso do Coffea congensis. No gráfico, os volumes (modos) desta espécie foram colocados na abcissa de 22 cromossômios e indicados com círculos. As ordenadas dêstes pontos indicam, com impressionante exatidão, que na realidade a abcissa deveria ser de 33 cromossômios. De fato, a equação de regressão e o "êrro de estimação" foram calculados com esta abcissa e assim os valores volumétricos da espécie "congensis" entram perfeitamente na série linear das demais formas estudadas. Não queremos com isto declarar que o C. congensis tenha 33 cromossômios; as contagens feitas precedentemente sôbre o mesmo material (Krug, 28) são isentas de qualquer dúvida. Podemos sòmente dizer que - volume modal dos núcleos de $C$. congensis correspondem a um valor do volume igual ao de "arabica" de genoma $3 x$.

Para verificar se as diferenças entre os valores de "arabica" e os de "congensis" são estatìsticamente significantes, isto $e$, se não poderiam ser determinadas pela variação casual do volume, podemos antes de tudo aplicar o êrro de estimação. Neste caso, o valor teórico do volume correspondente a 22 cromossômios, calculado pela equação de regressão é de 375 ; as duas raízes de "congensis" têm, respectivamente, os valores modais de volume de 615 e 669. As diferenças entre êstes valores e o valor teórico de 22 cromossômios são, respectivamente, 230 e 246, isto é, distintamente maiores que o limite de confiança da variabilidade casual $\pm 3 \mathrm{Sy}$, que é 198 . 

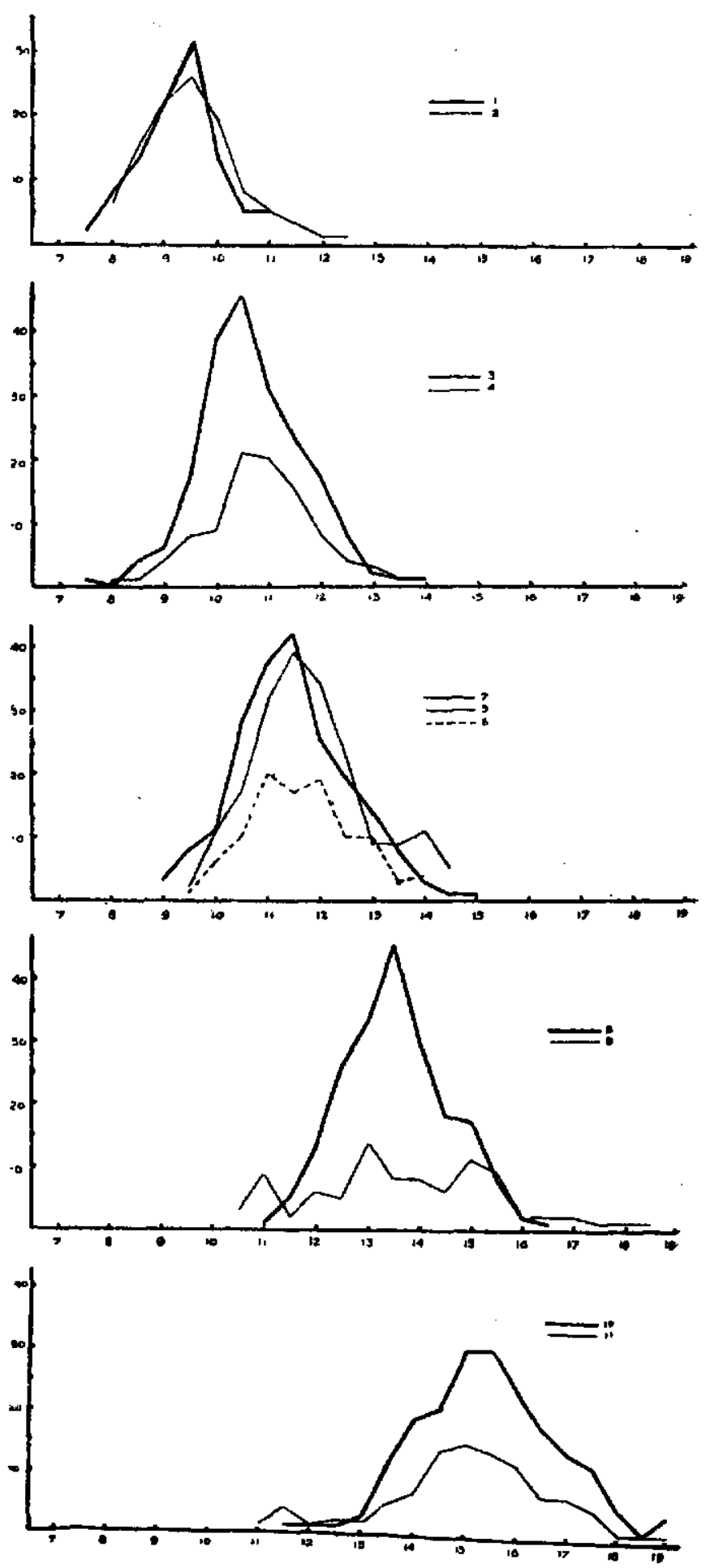

Gráfico $I$

Frequência dos volumes nucleares nos polipóides.

$1-2=22$ crom. (C. arabica v. monosperma).

$3-4=22$ crom. (C. congensis).

5-6-7 $=44$ crom. (C. arabica).

$8-9=66$ crom. $10-11=88$ crom. $(C$ arab. v. bullata $)$. 


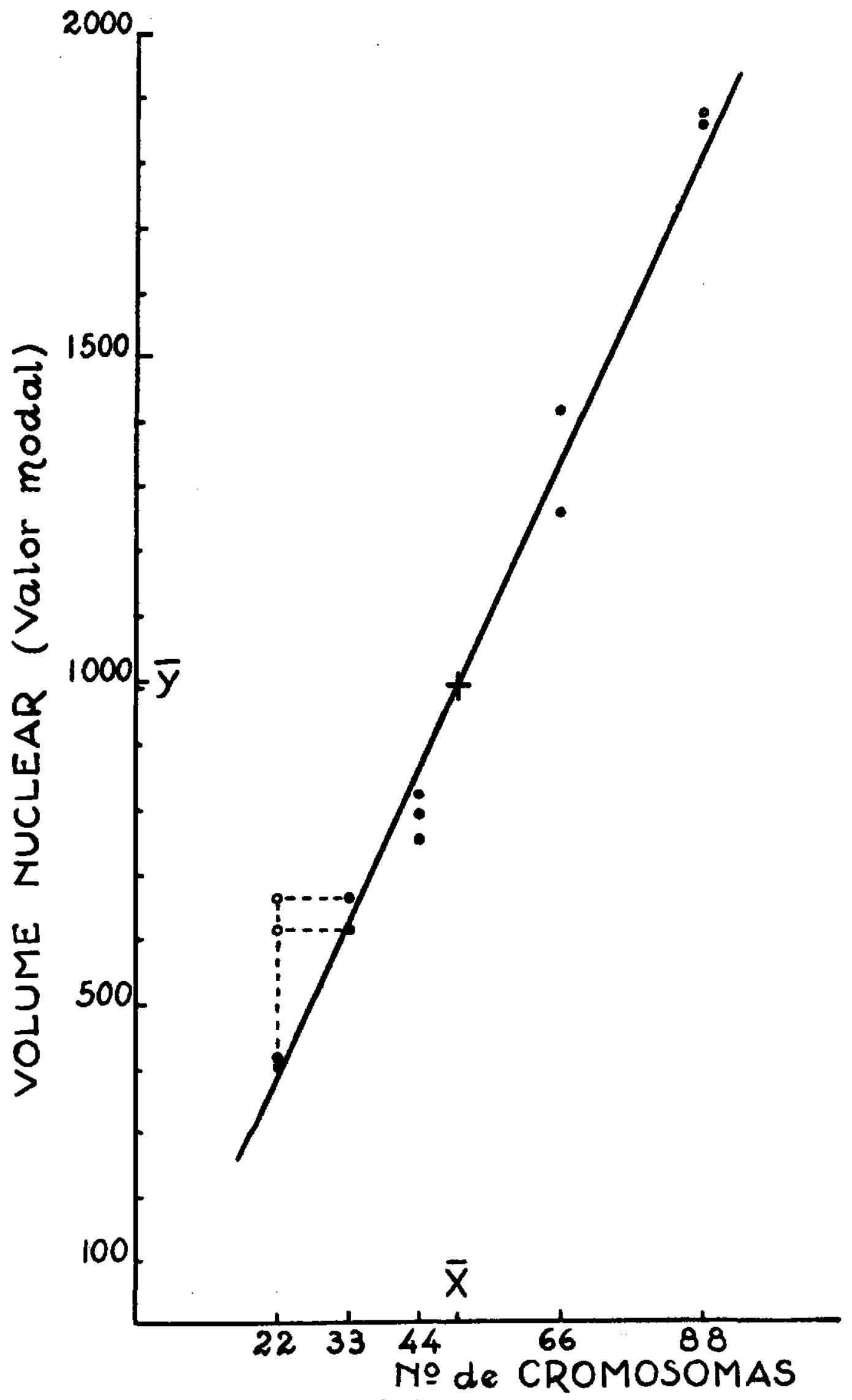

Gráfico II

Díagrama de correlação entre volume nuclear e número de cromossômios

$$
\mathrm{E}=\overline{\mathrm{y}}+220.8(\overline{\mathrm{x}}-\mathrm{x})
$$




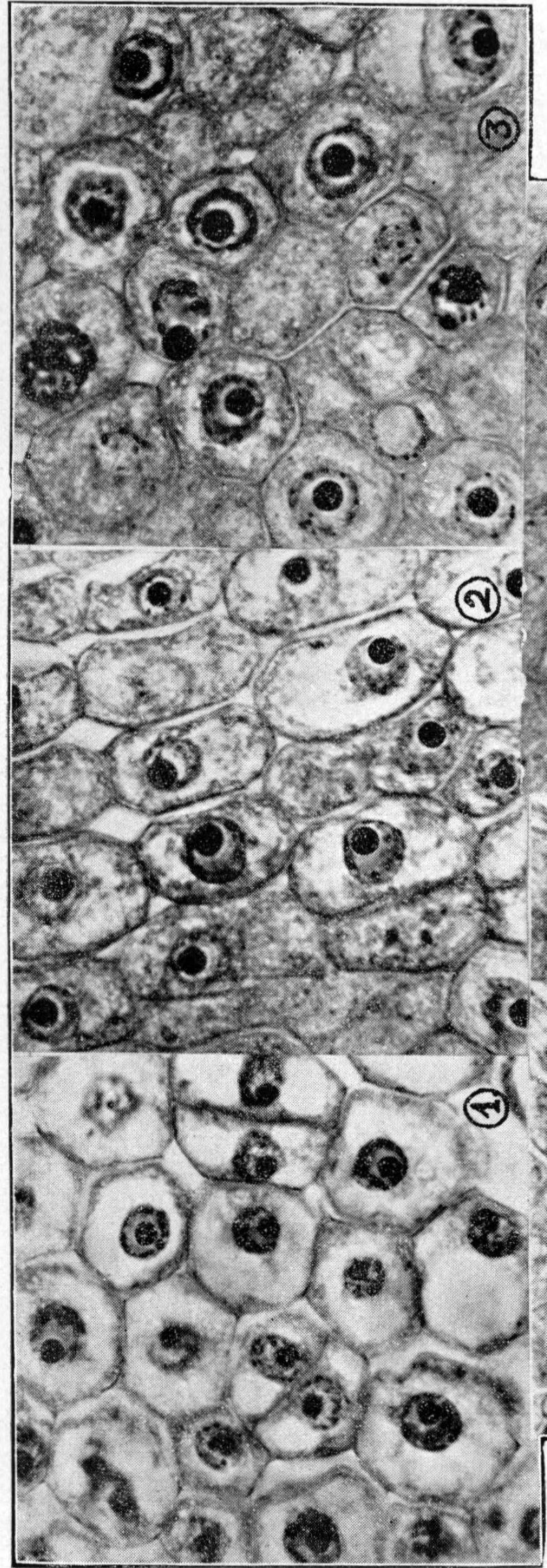

Explicação das microfotografias

Fig. 1. Coffea arabica v. monos-

perma $\ldots \ldots \ldots \ldots \ldots .2 \mathrm{n}=22$

Fig. 2. Coffea congensis $\ldots \ldots \quad 2 \mathrm{n}=22$

Fig. 3. Coffea arabica $\ldots \ldots .2 \mathrm{n}=44$
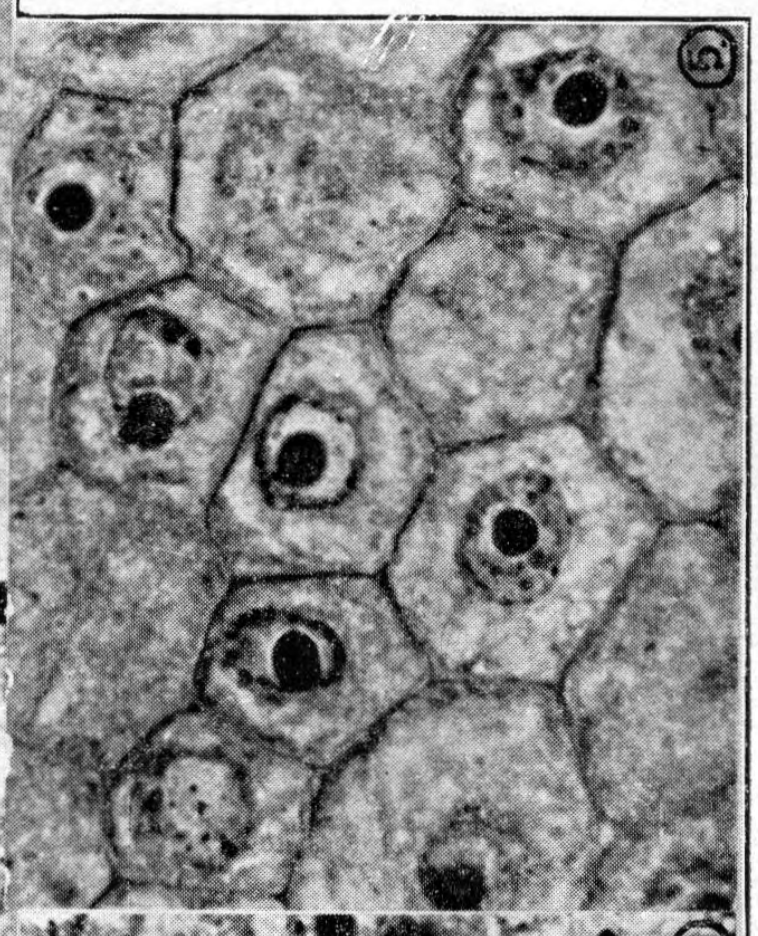

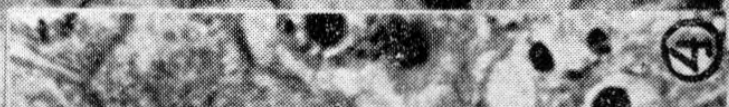

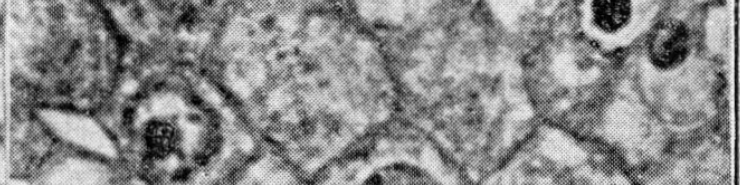

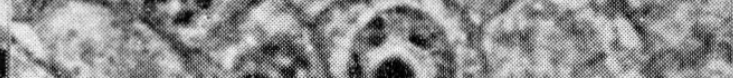

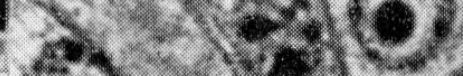

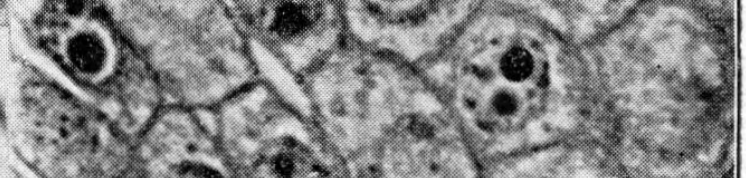

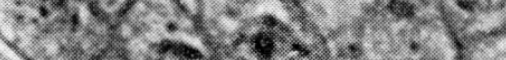

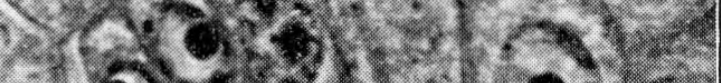

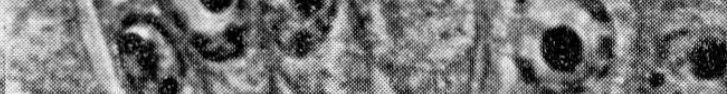

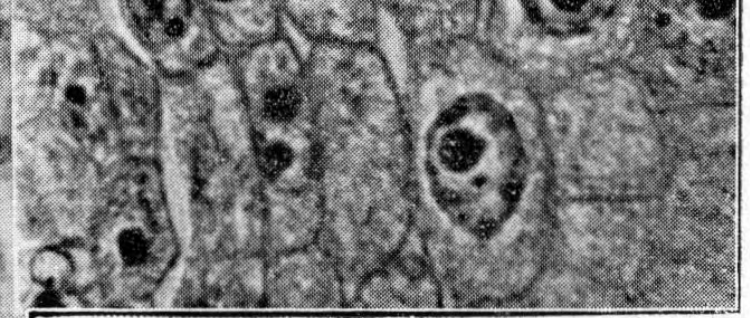

Fig. 4. Coffea arabica v. bullata $2 \mathrm{n}=66$ Fig. 5. Colfea arabica v. bullata $2 \mathrm{n}=88$

Cortes transversais de pontos vegetativos de raizes de Coffea. x 1500. 


\section{IV - CONCLUSÕES GERAIS E DISCUSSÃO}

Das premissas detalhadamente discutidas e dos gráficos de correlação podemos tirar a conclusão bastante legítima de que o volume dos núcleos na série poliplóide de Coffea é diretamente proporcional ao número de genomas, ou de cromossômios. Salientamos mais uma vez que esta proporcionalidade vale sòmente para os volumes "modais", isto é, para. o volume no qual os núcleos permanecem por um tempo mais longo durante a excursão interfásica (que abrange ao menos um intervalo de duplicação). Temos elementos para acreditar que estas fases são homólogas nas diferentes plantas e, portanto, a correlação é válida.

Estes resultados não devem ser considerados como novos, apesar de a enunciação acima ser dada de modo algo diferente do que é costume.

De fato, esta conclusão confirma uma série de indicações existentes: na literatura citológica, as quais ligam o volume do núcleo ao número de cromossômios. As presentes pesquisas, se bem que executadas com material não muito numeroso, e com as limitações já esclarecidas, dão a esta correlação uma confirmação mais significativa e mais comprovada do ponto de vista estatístico. Pelas mesmas razões, achamos interessante comentar: os resultados curiosos e discordantes de Coffea congensis. Não é aqui o lugar, nem é nossa tarefa discutir o caso muito profundamente. E preciso antes de tudo confirmar sôbre outras plantas o fenômeno e depois estudar mais detalhadamente a citologia desta espécie. Parece-nos, todavia, importante o fato de que uma pesquisa de citologia quantitativa pode criar assim um problema de genética e de sistemática que antes não fôra imaginado existir.

Trata-se de uma diferença especifica genética nas relações causais: entre o genoma e o volume nuclear? O mesmo número de cromossômios em $C$. arabica e em $C$. congensis determina, por diferenças gênicas, volumes. diferentes. Dobzhansky (15) mostrou em Drosophila a realidade dêste fator genético na determinação do tamanho celular ; é, porém, necessário salientar que aqui, como também nas pesquisas de Wettstein (42), se trata do tamanho celular e não nuclear, mas não vemos, contudo, por que êstefato exclua a possibilidade de um fato análogo para com o volume nuclear. Barigozzi (4), em Artemia, também verificou variaçōes de tamanho nuclear especificas independentes do número de cromossômios.

$O$ fato de ser o $C$. congensis outra espécie deveria ter a maior significação na interpretação da diferença dos volumes com $\circ C$. arabica, mas o que queremos salientar aqui é o fato de ser esta diferença um múltiplo exato do volume igual ao do haplóide de arabica, sem com isto pretender especificar qualquer relação qualitativa entre os genômios. das duas especies $\left(^{*}\right)$.

(*) Comentando esta discussão, o Dr. A. J. T. Mendes teve a gentileza de nos dar a kua opinião pessoal sôbre o assunto, a qual tomamos a liberdade de transcrever aqui :

"Na nossa constante observigão de material do gênero Coffea temos: notiulo que em várias espécies diplóides $(2 n=22)$ os cromossômios são: 
Deixando, portanto, o caso "congensis" como uma indicação para ulteriores estudos citogenéticos, podemos concluir que a análise estatística de um grupo de plantas poliplóides de grau progressivo de poliploidia nos proporciona uma correlação evidente e significante entre o volume nuclear e o valor múltiplo do genoma.

Esta conclusão, juntamente com aquelas tiradas do estudo da série espermatogenética nos autorizam a acreditar no valor das medidas cariométricas como meio, seja mesmo bem grosseiro de estudo das variações descontínuas do genoma durante os delicados e fundamentais processos de duplicação que se verificam durante a interfase. Estes estudos, portanto, devem sempre ser considerados estritamente no sentido de que só são válidas as medidas quando confrontadas em fases homólogas do ciclo interfásico.

A existência da "sesquífase" que confirmamos no ciclo da espermatogonia nos sugere a possibilidade de analisar no futuro, sob êste ponto de vista crítico, as várias indicações na literatura, que discordam no que se refere à relação direta entre genoma e volume nuclear.

\section{$\mathrm{V}-\mathrm{R}$ ES U M O}

Foi estudado o volume nuclear de uma série de plantas de café com 22-44-66-88 cromossômios : C. congensis, C. arabica var. monosperma, C. arabica var. typica e C. arabica var. bullata e pelo método estatístico cariométrico. Das curvas de frequência (que não são "normais"), foi calculado o valor normal (modo) para cada nùmero de cromossômios.

Com êstes valores modais e os respectivos números de cromossômios foi calculada a equação de regressão, o êrro de estimação e o coeficiente de correlação.

A correlação é perfeita, sendo, porém, a espécie $C$. congensis discordante dos demais elementos da série por ter um valor volumétrico correspondente a 33 cromossômios apesar dos 22 encontrados nas metáfases somáticas. Este resultado é apontado para ulteriores investigações citogenéticas sôbre esta espécie.

de um modo geral maiores que os da espécie $C$. arabica $(2 \mathrm{n}=44)$. Esta diferença, todavia, $c$ evidente no sentido do comprimento dos cromossômios e não na espessura ; isso nos leva a crer que não deve haver diferença em $n .{ }^{\circ}$ de cromonemas de uma espécie para outra, mas sim uma diferença de cromossômiós inteiros. de $C$. arabica não tome parte qualquer cromossômio de $C$. congensis. Aliás, já conseguimos duplicar o n.o de cromossômios de um híbrido entre $C$. congensis e $C$. laurentii e o tetraploide obtido não se assemelha ì espécie C. arabica.

Foi baseado na diferença de tamanho existente entre os cromossômios das diversas espécies que, em 1938, eu escolhi a espécie C. excelsa para iniciar um estudo da morfologia e das dimensões, dos cromossômios de Coffea. A espécie C. excelsa 6 , das diploides, a que aparentemente tem cromossômios mais longos.

Talvez a melhor explicação para o fato da extranha relação encontrada para $C$. congensis seja a de que os cromossômios desta espécie são, de um modo geral, 1,5 vêzes mais longos que os da espécie C. arahica". 
O resultado geral destas pesquisas mostra a perfeita correlação entre o número de genomas haplóides e o volume nuclear; deve ser considerado, porém, válido sòmente no confronto entre núcleos que se encontram na mesma fase do ciclo de crescimento interfásico.

\section{S U M M A R Y}

Caryometric researches on Coffea polyploids. General discussion of the problem and preliminary results.

A series of polyploid plant of Coffea with 22, 44, 66, and 88 chromosomes (C. congensis, C. arabica var. monosperma, C. arabica var. typica, C. arabica var. bullata) have been studied with caryometric statistical method. The chromosome numbers have been plotted against the modal value of the frequency curves of nuclear volume and the regression equation, standard error of estimation and correlation coefficent have been calculated.

The correlation results perfect between the chromosome number and the nuclear volume for all the elements of the polyploid series of Coffea arabica. Coffea congensis, althought with 22 chromosomes, has a nuclear volume exactly correspondent to that of C. arabica with 33 chromosomes. This fact is appointed for further investigations.

As general result is emphasized the confirmation of the strict relation between nuclear volume and the multiple value of the haploid genome (number of chromosomes) but the result must be considered valid only when the nuclei are confronted at the ame phase of the interphasic growth cycle.

\section{I T E RA T U RA C I TA DA}

1. Artom, C. Le basi citologiche di una nuova sistematica del gen. Artemia. Arch. Zellf. 13 (9) : 87-113, 1913.

2. Barigozzi, C. Cytogenetical analysis of two wild populations of Artemia salina in connection with polyploidism. Proceed. 7 th Intern. genetical Congress Edinburgh. 1939. Jour. of Genetics Suppl. 28.

3. Barigozzi, C. Relazione fra numero cromossomico e grandezza nuclare in Artemia salina Leach. Scienza Genetica II. 1940.

4. Beams, H. W. e R. L. King The origin of binucleate and argel mononucleate cells in the liver of the rat. - The Anat. Record 83 (2): 271-297. 1942.

5. Berger, C. A. On the origin and fate of different types of polyploid nuclei. Proceed. 7th Intern. Genetical Congress Edinburgh. Journ. of Genetics 28. 1939.

6. Berger, C. A. Reinvestigation of polysomaty in Spinaces. Bot. Gazette 102 : 759. 1940.

7. Berger, C. A. Some criteria for judging the degnee of polyploidsm of cells in the resting stage. Am. Natur. 75 : 93.1941.

8. Berger, C. A. Multiple chromosome complexes in animal and polysomaty in plants. Cold Spring Harbor Symposia on Quant. Biol. IX. 19, 1941.

9. Berger, C. A. A new criterious of the degree of poliploidy of $\}$ the "resting" nuclei. Genetics 26: 1941 (abstract).

10. Berger, C. A. A cytological study of the prophases of meiosis and the prophases of the tetraploid and octoploid somatic cells of the root of spinach. Year Book of the Amer. Philos. Soc. 166 : 67. 1943.

11. Bhaduri, P. N. Application of new technique to cytogenetical reinvestigation of the genus Tradescantia. Journ. of Genetics 44 (91) : 87-127. 1942.

12. Biesele, J. J., H. Poyner e T. Painter. Nuclear phenomena in mouse cancer. The University of Texas Publications N. ${ }^{\circ} 4243.1942$. 
13. D'Ancona, U. Grandezze nucleari e poliploidismo nelle cellule somatiche, Monitore zoologico Italiano. L. (8-9) 225 : 231, 1939.

14. D'Ancona, U. Sul poliploidismo delle cellule epatiche. Boll. Soc. Ital. Biologia Sperim. 16 (1) : 49-50. 1941.

15. Dobzhansky $T$. The influence of the quantity and quality of chromosomal materias on the size of the cells of Drosophila melanogaster. Roux's Arch. f. Entwicklungs. mech. 115. 363-370. 1928.

16. Erwin, C. D. A study of polysomaty in Cucurbis melo. Am. Journ. Bot. 28 : 113. 1941.

17. Fankhauser, G. The effect of changes in chromosome [number on anphibian development. The Quart. Rev. of Biol. 20 (1) : 20-78. 1945.

18. Fischer, I. Ueber den Wachstumsrhytmus des Follikelepithels der Lause und Federlinge und ihre Beziehungen zum Arbeitsrhytmus der Zellen und zur Amitose. Arch. Zellf. Mikr. Anat. 23 : 218. 1936.

19. Freerksen, E. Ein neuer Beweis fuer das rhytmische Wachstum der Kerne durch vergleichende volumetrische Untersuchungen an den Zellkerne vom Meerschweinchen und Kaninchen. Zur Zellf. und mikr. Anat. 18. 1933.

20. Geitler, L. Das Wachstum des Zellkernes im tierischen und pflanzlichen Gewebe. Ergebnisse der Biologie. 18 : 1-54. 1941.

21. Gentscheff, G. e A. Gustaffson The double chromosome reproduction in Spinacia and its causes. I-II Hereditas. 25:349. 1939.

22. Godlewsky E. Compt. Rendus. Soc. de Biologie Réun. Plén. 24 avril 1925 cit. de Huxley J. - De Beer G. R. De Flements of Experimental Embriologia Cambridge 1934.

23. Hertwig, G. Die dritte Reifeteilung in der Spermiogenese des Menschen und der Katze Ztch. mikr. anat. Forsch. Bd. 33. 1933.

24. Krug, C. A. Contribuição para o estudo da citologia do gênero Coffea. Boll. técn. Inst. Agronômico de Campinas N.० $11: 1-8.1934$.

25. Krug, C. A. Estudos citológicos em Coffea. II. Bóll. Técn. Inst. Agronômico de Campinas n. $22: 1-5.1936$.

26. Jakohi, W. Ueber das rhytmische Wachstum der Zellen durch Verdoppelung ihre Volumens. Arch. f. Entw. Mech. 106. 1925.

27. Jakobi, W. Ueber das Wachstum der Zellen nach einem Gesetz der konstanten. Proportionen. Muenchn. Med. Woch. 20 : 850. 1926.

28. Jakobi, W. Volumetrisclie Untersuchungen an den Zellkernen des Menschen und das alıgemeine Problem der Zellkerngroesse. Anat. Anz. 72 : 1931.

29. Langlet, O. Zur Kenntnis der polysomatischen Zellkernen in Wurzelmeristem. Swensk. Bot. Tidsch. 21. 169. 1927.

30. Mendes, A. J. T. e O. Bacchi Observações citológicas em Coffea V. Uma variedade haplóide (di-haplóide) de C. arabica L. Boll. Técn. Inst. Agronómico de Campinas N.० 77. Jornal de Agronomia 3 (3) : 183-206. 1940.

31. Meyer, R. Zur Statistik der Verteilung nuklearer Stoffe. Zugleich eine Kritik der bisherigen variations statistischen Untersuchungen der Kernvolumina. Ztschr. Zellf. u. mikr. Anat. 25 : 353. 1937.

32. Sauser, G. Die Groesse der Zellkerne in vergleichenden Tierklassen unter Beruecksichtigung des Geschlechtes, der Domestikation und Kastration. Zur Zellf. und mikr. Anat. 23 : 681.1936.

33. Schreiber B. Ricerche sulla Spermatogenesi accelerata della Anguilla. Archiviozoologico italiano. 24 : 147-167. 1937.

34. Schreiber, G. O volume do núcleo durante o desenvolvimento embrionário e a interfase. Revista de Agricultura 18 : (11-12) 453-474. (Semana de Genćtica, Piracicaba) 1943. 
35. Sehreiber, G. Pesquisas de citologia quantitativa: o crescimento interfásico da espermatogonia nos Ofídeos. Revista Brasileira de Biologia. 1946.

36. Sulkin, Norman M. A study of the nucleus in the normal and hyperplastic liver of the rat. Am. J. Anat. 73 (1) : 107-125, 1943.

37. Thompson, D'Arey W. On growth and form. New Edit. Cambridge University Press. 1942.

38. Wermel E. Studien ueber Zellengroesse und Zellenwachstum. IV. Mitt. Üeber dimensionender Samenzelleu u.s.w. dos Seiden raupen. Z. zell. u. mikr. anat. 17. 1933.

39. Wermel, E. e W. W. Portugalow Studien ueber Zellengroesse und Zellenwachstum. XII. Mitt. Ueber d. Nachweis des rhytmischen Zellenwachstums. Zt. Zellf. u. mikr. Anat. 22 : 183.1935.

40. Wettstein F. von Kreuzungsversuche mit multiploiden Moosrassen II. Biol. zb]. 44. 1924.

41. Wilson E. B. The cell in development and Heredity. 3a Ed. 1940.

42. Witkuss, E. R. Endomitosis in Plants. Biol. Bull. 8 : 191, 1945. (Abstract). 


\begin{tabular}{|c|c|c|c|c|c|c|c|c|c|c|c|c|}
\hline & 号 & 8 & $\stackrel{-1}{\circ}$ & $\ddot{~}$ & 8 & 8 & \&్ㄱㅁ & ళ్సి & $\stackrel{8}{-}$ & $\infty$ & $\stackrel{\infty}{\stackrel{9}{2}}$ & \& \\
\hline & $\begin{array}{l}102 \\
\sigma^{2}\end{array}$ & & & & & & & & & & & \\
\hline & 9 & & & & & & & & & & + & - \\
\hline & $\begin{array}{l}10 \\
\infty^{10}\end{array}$ & & & & & & & & & $\pi$ & $\rightarrow$ & $r$ \\
\hline & $\stackrel{\infty}{\sim}$ & & & & & & & & & - & 10 & $\rightarrow$ \\
\hline & 5 & & & & & & & & & - & $\boldsymbol{\Psi}$ & 10 \\
\hline & $\approx$ & & & & & & & & & $\sqrt{N}$ & $\exists$ & $N$ \\
\hline & 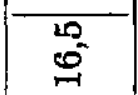 & & & & & & & & - & $N$ & $\stackrel{\infty}{=}$ & $N$ \\
\hline 瑟 & $\mathscr{2}$ & & & & & & & & $\bar{N}$ & $\mathbf{N}$ & J & $\approx$ \\
\hline 8 & 告 & & & & & & & & $\infty$ & $\infty$ & $\vec{m}$ & $\exists$ \\
\hline 离 & 19 & & & & & & & -1 & $\cong$ & 9 & $\overrightarrow{\sigma r}$ & $\stackrel{10}{-19}$ \\
\hline 番 & $\stackrel{22}{ \pm}$ & & & & & 10 & & $\rightarrow$ & $\stackrel{\infty}{\infty}$ & $\infty$ & $\vec{N}$ & $\nexists$ \\
\hline 島 & $\exists$ & & & -1 & & $=$ & $\pi$ & $\infty$ & p & 오 & $\stackrel{2}{2}$ & $N$ \\
\hline 是 & פ20 & & & $\neg$ & & $\infty$ & $\infty$ & $\infty$ & $\stackrel{29}{4}$ & 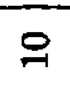 & $\cong$ & 10 \\
\hline$\underset{\mathscr{z}}{\stackrel{\vartheta}{\epsilon}}$ & $\dddot{9}$ & & & $N$ & $\Rightarrow$ & 0 & 옥 & $\exists$ & ణొ & $\exists$ & $\infty$ & $N$ \\
\hline$\sum$ & $\stackrel{1}{a}$ & & $\neg$ & $\infty$ & $\infty$ & สิ & 음 & $\stackrel{2}{2}$ & สี & 10 & -1 & N \\
\hline 焉 & $\cong$ & & - & $\cong$ & $\infty$ & है & 9 & เด & $m$ & 0 & 7 & -1 \\
\hline$\stackrel{\circ}{\circ}$ & $\stackrel{10}{=}$ & & $\infty$ & ఇ & 12 & 吕 & $\simeq$ & 아 & 10 & ヘ & - & $H$ \\
\hline 동 & $\exists$ & 20 & 10 & $\overrightarrow{\text { m. }}$ & శ్ & $\vec{m}$ & 오 & 闩 & $r$ & $\infty$ & & -1 \\
\hline 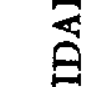 & 10 & 10 & $\infty$ & $\stackrel{29}{7}$ & $\overrightarrow{\mathrm{N}}$ & $\approx$ & 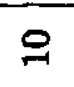 & $\stackrel{\infty}{\Delta}$ & & n & & \\
\hline 舅 & 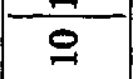 & $g^{\prime \prime}$ & $\Phi$ & $\infty$ & $\infty$ & $\exists$ & 0 & $\exists$ & & & & \\
\hline 空 & 10 & $\bar{\omega}$ & $\mathbb{8}$ & $\simeq$ & $\infty$ & N & $\rightarrow$ & $\infty$ & & & & \\
\hline & 0 & న & న & 0 & $*$ & & & $\infty$ & & & & \\
\hline & $\infty$ & 2 & $\stackrel{2}{2}$ & + & - & & & & & & & \\
\hline & $\infty$ & $\infty$ & $\infty$ & 0 & - & & & & & & & \\
\hline & 5 & $N$ & & 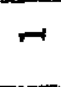 & & & & & & & & \\
\hline & 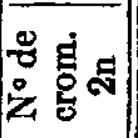 & జิ & జี & ્ָર & ָิ & J & $\$$ &  & 8 & $\nexists$ & $\underset{\infty}{\infty}$ & $\mathscr{\infty}$ \\
\hline & 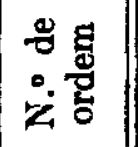 & $\tau$ & N & $\infty$ & ${ }^{*}$ & $\infty$ & $\infty$ & 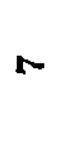 & $\infty$ & $\infty$ & 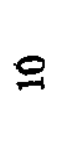 & $=$ \\
\hline
\end{tabular}


T A B E L A I I

Média aritmética (M) - Desvio padrão $(\sigma)$ e Coeficiente de variações $(V)$ dos: Diâmetros e dos Volumes nucleares

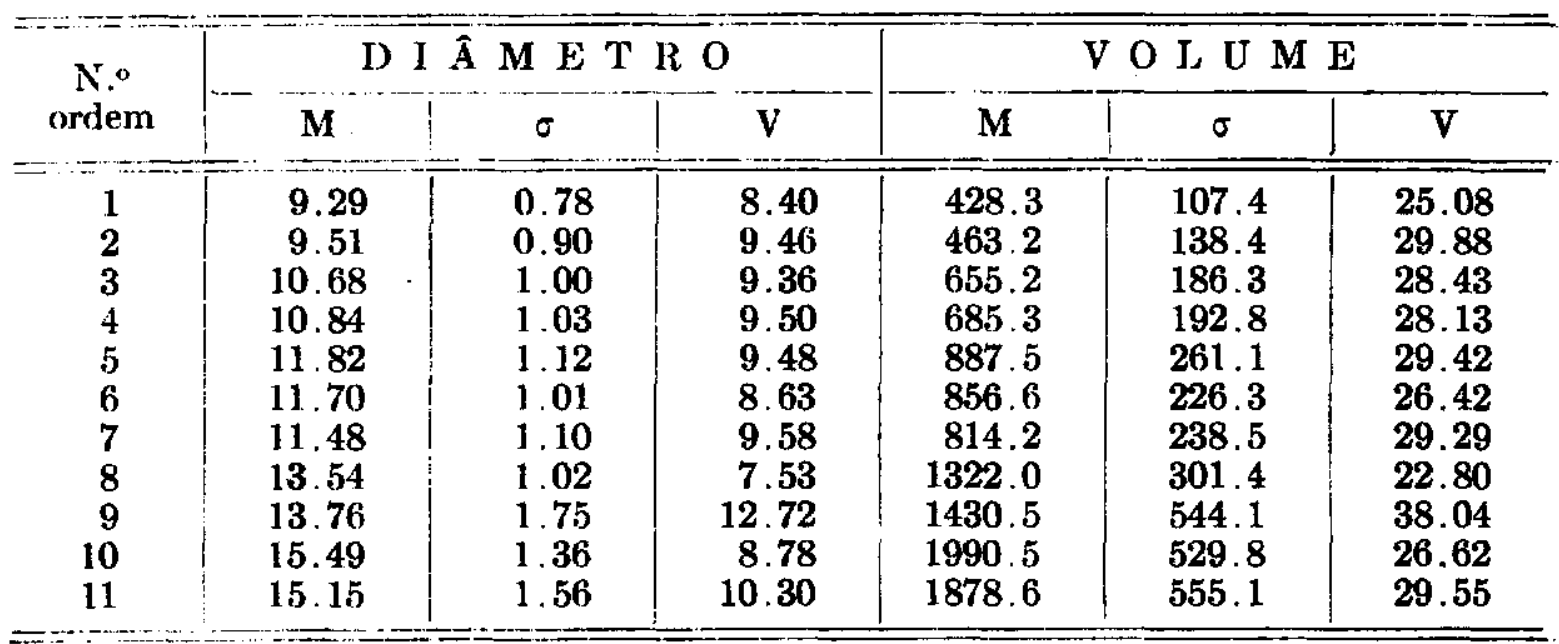

$\begin{array}{lllllllll}\mathbf{T} & \mathbf{A} & \mathbf{B} & \mathbf{E} & \mathbf{L} & \mathbf{A} & \mathbf{I} & \mathbf{I} & \mathbf{I}\end{array}$

Média Aritmética (M) - Valor Normal (Modo) e Valor Mediano dos Diâmetros. e dos Volumes Nucleares

\begin{tabular}{c|c|c|c|c|c|c|c}
\hline & \multicolumn{2}{|c|}{$\begin{array}{c}\text { D I A M E T R O } \\
\text { N. }\end{array}$} & \multicolumn{3}{|c|}{ V O L U M E } \\
\hline \begin{tabular}{c|c|c|c|c|c|c} 
Média \\
Aritmética
\end{tabular} & $\begin{array}{c}\text { Vol. } \\
\text { mediano }\end{array}$ & $\begin{array}{c}\text { Vol. } \\
\text { normal }\end{array}$ & $\begin{array}{c}\text { Média } \\
\text { Aritmética }\end{array}$ & $\begin{array}{c}\text { Vol. } \\
\text { mediano }\end{array}$ & $\begin{array}{c}\text { Vol. } \\
\text { normal }\end{array}$ \\
\hline 1 & 9.29 & 9.35 & 9.30 & 428.3 & 428.0 & 421.2 \\
2 & 9.51 & 9.45 & 9.35 & 463.2 & 441.9 & 428.0 \\
3 & 10.68 & 10.55 & 10.55 & 655.2 & 614.8 & 614.8 \\
4 & 10.84 & 10.85 & 10.85 & 685.3 & 668.8 & 668.8 \\
5 & 11.82 & 11.70 & 11.65 & 887.5 & 838.6 & 827.9 \\
6 & 11.70 & 11.65 & 11.50 & 856.6 & 827.9 & 796.3 \\
7 & 11.48 & 11.40 & 11.30 & 814.2 & 775.7 & 755.5 \\
8 & 13.54 & 13.45 & 13.40 & 1322.0 & 1274.0 & 1259.8 \\
9 & 13.76 & 13.75 & 13.95 & 1430.5 & 1361.2 & 1421.4 \\
10 & 15.49 & 15.40 & 15.30 & 1990.5 & 1912.3 & 1875.3 \\
11 & 15.15 & 15.20 & 15.25 & 1878.6 & 1838.8 & 1857.0 \\
\hline
\end{tabular}

T A B E L A I I V

Razão entre o Vol. Nuclear e o N. ${ }^{\circ}$ de Cromossômios

\begin{tabular}{|c|c|c|}
\hline N.o de ordem & $2 n$ & Volume $(\operatorname{modo}) / 2 \mathrm{n}$ \\
\hline 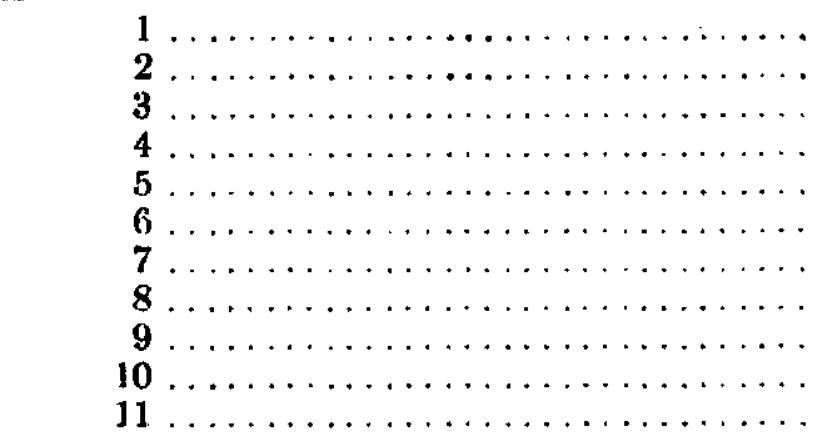 & $\begin{array}{l}22 \\
22 \\
(33)^{*} \\
(33)^{*} \\
44 \\
44 \\
44 \\
66 \\
66 \\
88 \\
88\end{array}$ & $\begin{array}{l}19.22 \\
19.45 \\
18.60 \\
20.26 \\
18.82 \\
18.09 \\
17.17 \\
19.08 \\
21.53 \\
21.31 \\
21.10\end{array}$ \\
\hline
\end{tabular}

(*) C. Congensis. Valor múltiplo do genoma conforme a figura II. 